\title{
DETERMINAN FAKTOR YANG BERHUBUNGAN DENGAN KINERJA BIDAN DALAM PROGRAM PERENCANAAN PERSALINAN DAN PENCEGAHAN KOMPLIKASI (P4K)
}

\author{
Sri K ustiyati \\ Sekolah Tinggi IImu K esehatan 'Aisyiyah Surakarta \\ (atik.nian@gmail.com, 087812858880)
}

\begin{abstract}
ABSTRAK
L atar Belakang: Progran Perencanaan Persalinan dan Pencegahan Komplikasi (P4K) merupakan salalh satu upaya untuk menurunkan angka kenatian ibu dan bayi. Keberkasilan program ini dipengaruhi oleh beberapa faktor, antara lain faktor karakteristik yang meliputij umur, pendidikan, masa kerja, serta faktor kemampuan yang meliputi pengetalhuan, inisiatiff dan silkap. Tujuan: Penelitian bertujuan untulk mengetahuli hulbungan unmur, pendidikan, masa kerja, pengetahuan, inisiatif dan sikap dengan kinerja bidan dalam pelaksanakan P4K. M etode: Jenis penelitian yang digunakan adalah observasional amalitik dengan pendekatan cross sectional. Penarikan sampel dengan proporsi cluster random sampling dengan besar sampel 43 orang. Analisa data menggumakan Chi Square H asil penelitian: hasil analisis data mentunjukkkan bahwwa fakktor yang berhulbungan dengan kinerja bidan adalah masa kerja (nilai p 0,005), sedangkan faktor yang lain tidak ada hulbungan, umur (nillai p 0,126), pendidikan (nilai p 0,497), pengetahuan (nilai p 0,266), inisiabif (nilai p 0,649) dan sikap (nilai p 0,716.) Simpulan: terdapat hulbungan masa kerja dengan kinerja bidan dalam pelaksanakan P4K di Kabupaten Sukoharjo.
\end{abstract}

Kata kunci: Masa kerja, kinerja bidan, kemanpuan, P4K

\begin{abstract}
Background Planning Program Delivery and Prevention Complication (P4K) is one effort to reduce maternal and infant mortality rate. The success of the program is affected by a number of factors, among other factors characteristic which includles age, education, length of employment, as well as the capability of being covering knowledge, the initiative and attitude Objective Research aimed at ascertaining the age of relations, education, length of enployment, knowledge, the initiative and attitude with the performance of the midwife in inforcenent P4K. Methods. The kind of research that is used is observational analytic with the approach cross sectional. Sampling with the proportion of cluster random sampling with a sample size of 43 people. Data were analyzed using Chi Square Result The data analysis showed that factors related to the performance of midwives are length of employment ( $p$ value 0,005 ), while the other factor is no relationship, age (p value 0.126), education (p value 0.497 ), knowledge (p value 0.266 ), initiative ( $p$ valkse 0.649 ) and attitude ( $p$ value of 0.716 .) Condusion: there is a relationship with the working lives of midwives" work in implementing P4K in Sulkoharjo disturict.
\end{abstract}

Passworct length of employment, the midwife performance, ability, P4K 
GASTER Vol. XV No. 1Februari 2017

\section{A. PENDAHUL UAN}

Program Perencanaan Persalinan dan Pencegahan Komplikasi (P4K) dilaksanakan dengan tujuan antara lain supaya ibu hamil dapat merencanakan persalinannya bersama-sama dengan keluarga dan penolong persalinan termasuk perencanaan mengikuti metode KB pasca melahirkan (Rachmawati, 2008). Dengan program P4K dapat diketahui kapan dan dimana persalinan ibu hamil serta bagaimana rencana persalinannya yang meliputi siapa penolong, pendamping dan pendonor darah kemudian sarana transportasi yang digunakan (Sedarmayanti: 2008). Dengan tercatatnya ibu hamil ini diharapkan cakupan persal inan oleh tenaga kesehatan dapat meningkat serta kejadian komplikasi dan kematian ibu menurun angkanya karena dapat diidentifikasi Iebih dini (Emerson, 2001).

Melalui P4K dengan stiker, masyarakat diharapkan dapat mengembangkan norma sosial bahwa cara yang aman untuk menyelamatkan ibu hamil, bersalin, nifas dan bayi lahir kebi dan atau tenaga kesehatan yang berwenang. Caranya dengan memeriksakan kehamilan, bersalin, perawatan nifas dan perawatan bayi baru lahir kebidan atau tenaga kesehatan terampil di bidang kebidanan. Berdasarkan uraian di atas jelas dikatakan bahwa salah satu pelaksana dalam program P4K ini adalah bidan (Depkes RI, 2009).

Tujuan umum dari program P4K adalah meningkatnya cakupan dan mutu pelayanan kesehatan bagi ibu hamil dan bayi baru lahir melal ui peningkatan peran aktif keluarga dan masyarakat dalam merencanakan persal inan yang aman dan persiapan menghadapi komplikasi dan tanda bahaya kebidanan bagi ibu sehingga melahirkan bayi yang sehat dengan bersal in di tenaga kesehatan (Depkes RI, 2009). Beberapa faktor keberhasilan kinerja bidan dalam program P4K antara Iain adalah faktor karakteristik meliputi umur, pendidikan dan masa kerja serta faktor kemampuan meliputi pengetahuan, inisiatif dan sikap bidan.

\section{B. BAHAN DAN METODE}

Desain penelitian yang digunakan adalah observasional analitik dengan pendekatan cross sectional. Penelitian dilakukan di Puskesmas Polokarto, Puskesmas Gatak dan Puskesmas Grogol di Kabupaten Sukoharjo dengan waktu pengambilan data pada bulan A pril-Mei 2015. Populasi dalam penelitian ini adalah seluruh bidan desa di Kabupaten Sukoharjo sebanyak 177 bidan desa. Sampel yang diambil 43 responden yang diperoleh dari Puskesmas Polokarto, Puskesmas Gatak, dan Puskesmas Grogol dengan menggunakan tehnik sampling proporsi cluster random sampling. Analisis data menggunakan Chi Square.

\section{HASIL PENELITIAN DAN PEMBAHASAN}

\section{Analisis Univariat}

Analisa univariat digunakan untuk menjelaskan karakteristik (umur, masa kerja, pendidikan), kemampuan (pengetahuan, inisiatif dan sikap) dan 
GASTER Vol. XV No. 1 Februari 2017

kinerja. Hasil analisa univariat sebagai berikut:

Tabel 1

Distribusi Frekuensi Karakteristik

Responden (Umur, Pendidikan dan

Masa Kerja), Kemampuan Responden

(Pengetahuan, Inisiatif dan Sikap), serta Kinerja

\begin{tabular}{llcc}
\hline No & \multicolumn{1}{c}{ Variabel } & Frekuensi & $\%$ \\
\hline 1. & Umur (tahun) & & \\
& $20-30$ & 18 & 41,9 \\
& $31-40$ & 20 & 46,5 \\
& $>40$ & 5 & 11,6 \\
\hline 2. & Pendidikan & & \\
& D1 & 2 & 4,7 \\
& D3 & 40 & 93 \\
& S2 & 1 & 2,3 \\
\hline 3. & Masa Kerja (tahun) & & \\
& $<$ & 4 & 9,3 \\
& 5-10 & 26 & 60,5 \\
& $11-20$ & 11 & 25,6 \\
& $>20$ & 2 & 4,7 \\
\hline 4. & Pengetahuan & & \\
& Kurang & 17 & 39,5 \\
& Cukup & 26 & 60,5 \\
& Baik & & \\
\hline 5. & Inisiatif & & \\
& Kurang & 6 & 14 \\
& Sedang & 37 & 86 \\
& Tinggi & & \\
\hline 6. & Sikap & & \\
& Negatif & 23 & 53,5 \\
Positif & 20 & 46,5 \\
\hline 7. & Kinerja & & \\
Cukup & 13 & 30,2 \\
& Baik & 30 & 69,8 \\
\hline
\end{tabular}

Sumber: Data Primer
Hasil penelitian menunjukkan bahwa sebagian besar besar responden berumur 31-40 tahun (46,5\%), berpendidikan D3 (93\%), masa kerja 5-10 tahun $(60,5 \%)$, berpengetahuan cukup (60,5\%), inisiatif sedang (86\%), dan kinerja baik (69,8\%).

\section{Analisis Bivariat}

Analisa bivariat digunakan untuk mengetahui hubungan variabel karakteristik (umur, pendidikan, masa kerja), dan kemampuan (pengetahuan, inisiatif dan sikap) dengan kinerja bidan dalam pelaksanaan P4K di Kabupaten Sukoharjo. Uji yang digunakan pada analisis bivariat ini menggunakan uji Chi Square dengan ketentuan bahwa apabila nilai $\mathrm{p}<0,05$ maka $\mathrm{Ho}$ ditolak dan $\mathrm{Ha}$ diterima. 
GASTER Vol. XV No. 1Februari 2017

Tabel 2

Hubungan Karakteristik (umur, pendidikan, masa kerja) dengan K inerja B idan

Dalam Pelaksanaan P4K di K abupaten Sukoharjo

\begin{tabular}{|c|c|c|c|c|c|c|c|c|c|}
\hline \multirow{3}{*}{ Variabel } & \multicolumn{6}{|c|}{ Kinerja } & \multirow{2}{*}{\multicolumn{2}{|c|}{ Jumlah }} & \multirow{3}{*}{$\begin{array}{c}P \\
\text { Value }\end{array}$} \\
\hline & \multicolumn{2}{|c|}{ Kurang } & \multicolumn{2}{|c|}{ Cukup } & \multicolumn{2}{|c|}{ Baik } & & & \\
\hline & $\mathrm{F}$ & $\%$ & $\mathrm{~F}$ & $\%$ & $\mathrm{~F}$ & $\%$ & $\mathrm{~F}$ & $\%$ & \\
\hline Umur (tahun) & & & & & & & & & 0,126 \\
\hline $20-30$ & & & 8 & 44 & 10 & 56 & 18 & 100 & \\
\hline $31-40$ & & & 3 & 15 & 17 & 85 & 20 & 100 & \\
\hline$>40$ & & & 2 & 40 & 3 & 60 & 5 & 100 & \\
\hline Pendidikan & & & & & & & & & 0,497 \\
\hline D1 & & & 0 & 0 & 2 & 100 & 2 & 100 & \\
\hline D3 & & & 13 & 32 & 27 & 78 & 40 & 100 & \\
\hline S2 & & & 0 & 0 & 1 & 100 & 1 & 100 & \\
\hline Masa Kerja (tahun) & & & & & & & & & 0,005 \\
\hline$<5$ & & & 0 & 0 & 4 & 100 & 4 & 100 & \\
\hline $5-10$ & & & 11 & 42 & 15 & 58 & 26 & 100 & \\
\hline $11-20$ & & & 0 & 0 & 11 & 100 & 11 & 100 & \\
\hline$>20$ & & & 2 & 100 & 0 & 0 & 2 & 100 & \\
\hline
\end{tabular}

Sumber: Data Primer

Hasil analisis bivariat yang pekerjaan, baik sifatnya fisik maupun non ditunjukkan pada tabel 2 didapatkan hasil fisik. Pekerjaanyangbanyakmengandalkan bahwa faktor yang berhubungan dengan kinerja adalah masa kerja ditunjukkan dengan nilai p 0,005 ( $\varangle, 05)$, sedangkan variabel yang lain tidak berhubungan.

Dari tabel 2 menunjukkan bahwa faktor umur tidak berhubungan kinerja. Kaitan umur dengan kinerja adal ah karena umur akan mempengaruhi kondisi fisik, mental, kemampuan kerja dan tanggung jawab seseorang. Pada umumnya tenaga kerja yang berumur tua, mempunyai tenaga fisik yang lemah dan terbatas, sebaliknya tenaga keja yang berumur muda mempunyai kemampuan fisik yang kuat. Umur seseorang cukup menentukan keberhasilan dalam melakukan suatu fisik umumnya menggunakan tenaga kerja yang berumur muda, tetapi ada juga yang tidak, dan sangat tergantung dari jenis pekerjaan tersebut (Robbins, 2003)

Hasil survey di Amerika Serikat menunjukkan ternyata 93\% pekerja usia lanjut sama baiknya dengan usia muda (Surani, 2007). Dalam penelitian Halim tahun 2003 tentang faktor-faktor yang berhubungan dengan kinerja bidan desa dalam kegiatan Pelayanan Antenatal di Kabupaten Batang Hari Propinsi menyebutkan bahwa umur tidak berhubungan dengan kineja (Halim, 2006). Pekerjaan bidan dalam program perencanaan persalinan dan pencegahan

10 Determinan Faktor yang Berhubungan ... 
GASTER Vol. XV No. 1Februari 2017

komplikasi (P4K) dapat melibatkan tenaga baik fisik maupun non fisik, baik dal am memberikan pelayanan kehamilan, persalinan, nifas, bayi dan pelayanan keluarga berencana (KB). Kinerja yang dicapai bidan merupakan penggabungan antara dimensi fisik dan non fisik. Sehingga dapat dikatakan wajar dalam penelitian ini jika variabel umur tidak berhubungan dengan kinerja, artinya bidan yang berusia 20-30 tahun, 31-40 tahun ataupun $>40$ tahun dapat memberikan kinerja yang hampir sama.

Bidan yang berusia 20-30 tahun, dapat dikatakan merupakan bidan yang baru lulus dari pendidikan bidan dan baru bekerja, sehingga memiliki semangat dan idealisme yang tinggi akan tetapi sebagian besar dari mereka belum dapat menyatu dengan masyarakat dan sebagian kurang dipercaya oleh masyarakat. Bidan yang berusia $>40$ tahun dapat dikatakan semangatnya mulai berkurang dikarenakan usia yang semakin menua, daya ingat yang sudah mulai berkurang, akan tetapi memiliki pengalaman yang banyak dansudahmengetahui karakteristik masyarakat dan tahu cara-cara melakukan pendekatan kepada masyarakat. Sehingga tidak terdapat perbedaan yang bermakna antara kinerja bidan yang berusia muda dengan bidan yang berusia tua.

Hasil penelitian tentang pendidikan menunjukkan bahwa mayoritas responden berpendidikan D3 kebidanan (93\%). Pendidikan dapat mempengaruhi kinerja bidan. Berdasarkan hasil uji chi kuadrat menyatakan bahwa tidak ada hubungan antara pendidikan dengan kinerja bidan dalam program perencanaan persalinan dan pencegahan komplikasi (P4K), dapat dilihat dari nilai $p>0,05(0,497)$. Pendidikan merupakan salah satu faktor yang menentukan keberhasilan seseorang dalam bekerja. Makin tinggi pendidikan, umumnya produktivitas juga semakin tinggi. Hal tersebut berhubungan dengan cara menyelesaikan setiap masalah yang dihadapi dalambekerjadengan sol usi yang tepat, efektif dan efisien (Notoatmodjo, 2000). Namun dari hasil penelitian faktor pendidikan tidak menunjukkan hal yang berpengaruh secara signifikan terhadap kinerja bidan dalam P4K, ini dikarenakan semua bidan baik yang berpendidikan $D 1$ sampai DIV wajib mentaati kebijakan pemerintah untuk melaksanakan P4K.

Hail penelitian menunujukkan sebagian besar responden bidan (93\%) berpendidikan D III kebidanan. Hal ini sesuai dengan Peraturan Menteri Kesehatan Republik Indonesia Nomor 1464/Menkes/Per/X/2010 tentang izin dan penyelenggaraan praktik bidan yang menyatakan bahwa bidan yang menjalankan praktik mandiri harus berpendidikan minimal Diploma III (D III) kebidanan, walaupun masih ada 1 bidan yang masih berpendidikan $D$ I dan diharapkan kedepannya dapat meningkatkan pendidikannya ke jenjang yang lebih tinggi.

Lulusan pendidikan bidan sebelum tahun 2000 dan D III kebidanan, 


\section{GASTER Vol. XV No. 1 Februari 2017}

merupakan bidan pelaksana, yang memiliki kompetensi untuk melaksanakan praktiknya baik di institusi pelayanan maupun praktik perorangan. Lulusan pendidikan bidan setingkat Diploma IV/ S1 merupakan bidan professional, yang memiliki kompetensi untuk melaksanakan praktiknya baik di institusi pelayanan maupun praktik perorangan, namun mereka dapat berperan sebagai pemberi layanan, pengelola, dan pendidik. Hasil penelitian Miles dan Miles menyimpul kan bahwa intelegensi terus menerus berkembang dalam periode yang lebih lama pada orang-orang yang memperoleh pendidikan lebih tinggi daripada orangorang yang pendidikannya kurang (PP IBI, 2006 dan Notoatmodjo, 2000).

Semakin tinggi tingkat pendidikan seseorang maka akan lebih rasional dan kreatif serta terbuka dalam menerima adanya bermacam usaha pembaharuan dan dapat menyesuai kan diri terhadap berbagai pembaharuan. Tingkat pendidikan seseorang berpengaruh dal ammemberikan respon terhadap sesuatu yang datang dari Iuar (Surani, 2007). Jika dikaji dari hasil penelitian, bidan di Kabupaten Sukoharjo sebagian besar sudah memenuhi standar minimal pendidikan bidan, akan tetapi kinerja yang dihasilkan dalam program P4K sebagian besar masih termasuk dalam kategori cukup. Menurut hasil wawancara dengan beberapa bidan desa menyatakan bahwa hal ini salah satunya disebabkan oleh masi h banyak masyarakat yang lebih percaya dengan dukun, masih ada beberapa bi dan yang merasa kesul itan membangun kemitraan dengan dukun, masih dominannya peran orangtual mertua dal am pengasuhan bayi baru lahir, sebagian masih ada masyarakat dengan pendidikan rendah sehingga menyulitkan bidan dalam memberikan pendidikan tentang kesehatan. Berarti di dalam hal ini diperlukan suatu proses pemberdayaan masyarakat yang harus dilakukan secara serius oleh setiap pihak yang terkait di dal amnya.

Hasil penelitian tentang masa keja responden menunjukkan sebagian besar bidan dengan masa kerja 5-10 tahun (60,5 \%). Masa kerja dapat menggambarkan pengal aman seseorang dalam menguasai bidangtugasnya, padaumumnyaseseorang dengan pengalaman kerja yang banyak tidak memerlukan bimbingan kerja yang banyak tidak memerlukan bimbingan dibandingkan dengan seseorang yang pengal aman kerjanya sedikit. Masa kerja menunjukkan pengalaman bidan dalam praktik kebidanan.

Berdasarkan hasil uji chi kuadrat menyatakan bahwa terdapat hubungan antara masa keja dengan kinerja bidan dalam program perencanaan persalinan dan pencegahan komplikasi (P4K), dapat dilihat dari nilai $\mathrm{p} \varangle 0,05(0,005)$. Masa kerja seseorang mencerminkan pengalaman seseorang dalam bekerja. Semakin lama seseorang bekeja akan semakin terlatih dan terampil dalam melaksanakan pekerjaan (Robbins, 2003). Teori ini sesuai dengan hasil penelitian, 
GASTER Vol. XV No. 1Februari 2017

dimana kinerja baik paling tinggi terdapat pada bidan dengan masa kerja 5-10 tahun $(60,5 \%)$ disusul oleh bidan dengan masa kerja $11-20$ tahun $(25,6 \%)$, bidan dengan masa keja 0-5 tahun (9,3\%) dan bidan dengan masa kerja $>20$ tahun $(4,7 \%)$.

Masa kerja berkaitan erat dengan pengalaman-pengal aman yang didapat selama dalam menjalankan tugas, karyawan yang berpengalaman di pandang lebih mampu dalam melaksanakan tugas. Makin lama kerja seseorang kecakapan mereka akan lebih baik karena sudah dapat menyesuaikan diri dengan lingkungan pekerjaan (Mangkunegara, 2006). Pendapat lain menyatakan bahwa masa keja tidak berhubungan dengan kinerja seseorang, semakin senior seorang pekerja bukanlah berarti akan lebih baik kinerjanya dibandingkan pada pekerja yang senioritasnya lebih rendah. Banyak studi tentang hubungan senioritas karyawan dan produktifitas. Meskipun prestasi kerja seseorang itu bisa ditelusuri dari prestasi keja sebelumnya, tetapi sampai saat ini belum dapat diambil kesimpulan yang meyakinkan antara kedua variabel tersebut. Pengal aman kerja yang sudah lama, tetap belum menjamin bahwa mereka lebih produktif daripada karyawan-karyawan yang belum lama bekerja disitu (Surani, 2007).

Hasil peneltitian tentang kineja bidan menunjukkan kinerja bidan dalam pelaksanaan P4K di Kabupaten Sukoharjo sebagian besar bidan mempunyai kinerja baik (69,8\%). Hal ini menunjukkan bidan telah berhasil dalam dalam pelaksanaan P4K di Kabupaten Sukoharjo. Ukuran keberhasilan bidan dilihat dari hasil penelitian ratarata bidan telah mencapai 80\% dari target yang di bebankan. Hasil itu menunjukkan bidan telah mencapai atau melampaui target di bebankan.

Kinerja bidan pelaksanaan P4K di ukur melalui keberhasilan bidan dalam melaksanakan tugas pokok dan fungsi bidan desa yaitu: Meningkatkan cakupan dan mutu pelayanan kesehatan ibu hamil, pertolongan persalinan, perawatan nifas, kesehatan bayi dan anak balita serta pelayanan dan konseling pemakaian kontrasepsi serta keluarga berencana melalui upaya strategis antara lain: Posyandu dan Polindes, Menjaring selunuh kasus risiko tinggi ibu hamil, bersalin, nifas dan bayi baru lahir untuk mendapatkan penanganan memadai sesuai kasus dan rujukannya. 
GASTER Vol. XV No. 1Februari 2017

Tabel 3

Hubungan Kemampuan (pengetahuan, inisiatif dan sikap) dengan Kinerja Bidan Dalam Pelaksanaan P4K di Kabupaten Sukoharjo

\begin{tabular}{|c|c|c|c|c|c|c|c|c|c|}
\hline \multirow{3}{*}{ Variabel } & \multicolumn{6}{|c|}{ Kinerja } & \multirow{2}{*}{\multicolumn{2}{|c|}{ Jumlah }} & \multirow{3}{*}{$\begin{array}{c}P \\
\text { Value }\end{array}$} \\
\hline & \multicolumn{2}{|c|}{ Kurang } & \multicolumn{2}{|c|}{ Cukup } & \multicolumn{2}{|c|}{ Baik } & & & \\
\hline & $\mathrm{F}$ & $\%$ & $\mathrm{~F}$ & $\%$ & $F$ & $\%$ & $\mathrm{~F}$ & $\%$ & \\
\hline Pengetahuan & & & & & & & & & 0,266 \\
\hline Kurang & & & 3 & 18 & 14 & 82 & 17 & 100 & \\
\hline Cukup & & & 10 & 39 & 16 & 61 & 26 & 100 & \\
\hline Baik & & & & & & & & & \\
\hline Inisiatif & & & & & & & & & 0,649 \\
\hline Kurang & & & 1 & 17 & 5 & 83 & 6 & 100 & \\
\hline Sedang & & & 12 & 32 & 25 & 68 & 37 & 100 & \\
\hline Tinggi & & & & & & & & & \\
\hline Sikap & & & & & & & & & 0,716 \\
\hline Negatif & & & 8 & 34 & 15 & 66 & 23 & 100 & \\
\hline Positif & & & 5 & 25 & 15 & 75 & 20 & 100 & \\
\hline
\end{tabular}

Sumber: Data Primer

Kemampuan dalam penelitian ini mengacu pada teori yang dikemukakan olehHasley, bahwakemampuanterdiri dari pengetahuan, inisiatif dan sikap. Setelah dilakukan pengujian statistik dengan menggunakan uji chi kuadrat diperoleh hasil bahwa variabel pengetahuan, inisiatif, sikap serta kemampuan secara kesel unuhan tidak terdapat hubungan yang bermakna dengan kinerja bidan dalam program perencanaan persalinan dan pencegahan komplikasi.

Hasil penelitian menunjukkan bahwa pengetahuan tidak berhubungan dengan kinerja bidan, ditunjukkan dengan nilai p 0,266 $(>0,05)$. Dari 43 orang bidan, sebagian besar (60,5\%) mempunyai pengetahuan dengan kategori cukup, yaitu memperoleh skor diantara 41-
$75 \%$, selebihnya berpengetahuan kurang (39,5\%). Dilihat dari hasil diatas dapat disimpulkan bahwa pengetahuan bidan di Kabupaten Sukoharjo tentang program P4K berada pada rentang pertengahan, berarti masih di perlukan suatu usaha dari para pemangku kebijakan dalam hal ini Dinas Kesehatan agar pengetahuan bidan tentang program ini meningkat sehingga diharapkan kinerjanya dapat meningkat pula. Hal ini sesuai dengan hasil penelitian bahwa sebagian besar dari bidan (60,5\%) mempunyai kineja yang cukup dalam program P4K.

Hasil penelitian ini sesuai dengan pernyataan yang mengatakan bahwa pengetahuan merupakan sal ah satu faktor internal yang berpotensi kuat untuk meningkatkan kepatuhan, sehingga 


\section{GASTER Vol. XV No. 1 Februari 2017}

akhirnya dapat berpengaruh positif terhadap peningkatan kineja bidan, wal aupun secara statistik diperoleh hasil bahwa tidak terdapat hubungan yang bermakna antara pengetahuan dengan kinerja bi dan dal am program perencanaan persalinan dan pencegahan komplikasi (P4K), terbukti dari nilai $p 0,266$. Artinya tidak terdapat perbedaan yang bermakna dal am menghasilkan kinerja antara bidan yang memiliki pengetahuan baik dengan bidan yang memiliki pengetahuan kurang (Mangkunegara2006, dan Robbins, 2003).

Terbentuknya sutau perilaku baru terutama pada orang dewasa dimulai pada domain kognitif, dalam arti si subjek tahu terlebih dahulu terhadap stimulus yang berupa materi atau objek diluarnya sehingga menimbulkan pengetahuan baru pada subjek tersebut. A khi rnyarangsangan yang telah diketahui dan disadari sepenuhnya tersebut akan menimbulkan respons lebih jauh lagi yaitu berupa perilaku sehubungan dengan objek atau stimulus yang diterimanya (Notoatmodjo, 2000).

Berkaitan dengan hasil penelitian yang menunjukkan bahwa pengetahuan bidan tentang program P4K sebagian besar termasuk dalam kategori cukup, hal ini bisa terjadi karena banyaknya kegiatan pokok yang dijalankan oleh Puskesmas sebagai ujung tombak pelayanan di lapangan membuat penyerapan informasi kadang terlambat, termasuk informasi tentang program P4K kapada para bidan di desa.
Selanjutnya hasil penelitian tentang inisiatif bidan dalam program perencanaan persalinan dan pencegahan komplikasi menunjukkan bahwa inisiatif tidak berhubungan kineja bidan dalam pelaksanaaan P4K, ditunjukkan dengan nilai p 0,649 $(>0,005)$. Sebagian besar inisisatif bidan di Sukoharjo dalam kategori cukup (86\%) dan sebagian kecil kategori kurang (14\%). Prosentase bidan yang berkinerja baik terdapat pada bidan dengan inisiatif cukup (58\%) dan terendah pada bidan dengan inisiatif kurang (12\%).

Setiap bidan tentu mempunyai pengalaman yang berbeda dalam menghadapi masalah pekerjaanya. Ada bidan yang mampu memahami profesinya dan berupaya untuk menjalankan pekerjaannya sebaik mungkin, mencoba mengatasi kesulitan dalam pekerjaan. Ada juga bidan yang bekerja hanya sebatas menjalankan kewajiban sebagai pegawai negeri si pil demi kesejahteraan hidupnya tanpa ada hasrat untuk berprestasi dibidang profesinya. Bidan yang merasa puas dengan status kepegawai annya hanya menjalankan rutinitas sebagai pegawai puskesmas.

Inisiatif dalam pengadaan stiker sangat diperlukan, mengingat persediaan stiker dari Dinas Kesehatan dalam kondisi terbatas. Stiker ini berfungsi sebagai alat notifikasi yangbermanfaat bagi masyarakat untuk mengetahui tempat tinggal ibu hamil, dan sebagai bukti bahwa bidan telah melaksanakan konseling tentang persiapan persalinan pada ibu hamil. Maka 


\section{GASTER Vol. XV No. 1 Fedruari 2017}

perlu kiranya ada himbauan atau dorongan dari Dinas Kesehatan atau Puskesmas kepada bidan desa dan masyarakat untuk berinisatif membuat sendiri alat notifikasi ibu hamil ini.

Hasil penelitian tentang sikap menunjukkan bahwa dari 43 orang bidan yang menjadi responden penelitian sebagian besar memiliki sikap negatif (53,5\%) dan secara statistik menunjukkan bahwa tidak ada hubungan yang bermakna antara sikap dengan kinerja bidan, dapat dilihat dari nilai p 0,716 $(>0,005)$. Faktor-faktor penentu kinerja adalah faktor individu dan faktor lingkungan organisasi dengan kemampuan (ability) yaitu pengetahuan yang dimiliki bidan dan keterampilan dalam memberikan pelayanansesuai dengan standarakanlebih mudah mencapai kinerja yang maksimal, dan dengan adanya motivasi (motivation) dan bersikap positif (pro) terhadap situasi kerjanya akan menunjukkan motivasi kerja tinggi, namun sebaliknya jika bidan bersikap negatif (kontra) terhadap situasi kerjanya akan menunjukkan motivasi kerja yang rendah (Mangkunegara, 2006 dan Winardi, 2008).

Pendapat diatas sesuai dengan hasil penelitian ini bahwa prosentase kinerja baik yang paling tinggi temyata terdapat pada bidan yang memiliki sikap yang positif terhadap kerjanya, meskipun sebagian besar bidan mempunyai sikap yang negatif. Sikap mental bidan yang positif (pro) terhadap situasi kerja inilah yang akan memperkuat motivasi kerjanya untuk mencapai kinerja maksimal. Sikap bidan haruslah memiliki sikap mental yang siap sedia secara psikofisik (siap secara mental, fisik, situasi dan tujuan) dalam memberikan pelayanan agar tuntutan masyarakat tentang pelayanan yang berkual itas dapat terlaksana dengan baik dan mutunya dapat terus ditingkatkan (Basri, 2004).

Tidak terdapatnya hubungan yang bermakna antara sikap dengan kinerja bidan dalam penelitian ini mengandung arti bahwa tidak terdapat perbedaan antara kinerja bidan dalam program P4K antara bidan yang memiliki sikap positif dan negatif. Diharapkan ada suatu metode pembinaan yang dilaksanakan untuk membuat persepsi positif bidan terhadap tugas-tugas yang diberikan kepadanya, mengingat sebagian besar $(53,5 \%)$ bidan memiliki sikap negatif terhadap P4K.

\section{SIM PULAN DAN SARAN}

Terdapat hubungan masa kerja dengan kinerja bidan dalam pelaksanaan Program Perencanaan Persalinan dan Pencegahan Komplikasi (P4K) di wilayah kabupaten Sukoharjo, sedangkan faktor umur, pendidikan, pengetahuan, inisiatif dan sikap bidantidak berpengaruhterhadap pelaksanaan P4K di wilayah tersebut.

Diharapkan ada suatu metode pembinaan yang dilaksanakan di kabupaten Sukoharjo untuk membuat persepsi positif bidan terhadap tugas-tugas yang diberikan kepadanya, mengingat sebagian besar bidan memiliki sikap negatif terhadap P4K. 
GASTER Vol. XV Nö. 1Fëbruari 2017

\section{DAFTAR PUSTAKA}

Basri, Rivai. 2004. PerformanceAppraisal. Jakarta: PT Raja Grafindo Persada.

Depkes RI. 2009. Pedoman ProgramPerencanaan dan Pencegahan Komplikasi dengan Stiker. Jakarta: Depkes RI.

Emerson. 2001. "Performance Measurement Matters". J ournal Of PmTeam Vol. 4, No. 2.

Halim 2006. Faktor-Faktor yang Berhubungan dengan Kinerja Bidan Desa dalamKegiatan

Pelayanan Antenatal di Kabupaten Batang Hari Propinsi J ambi Tahun 2006 [diunduh tanggal 16 April 2011]. Tersedia dari: http://eprints.undip.ac.id/5539/1/1686/pdf.

Mangkunegara AAAP. 2006. Evaluasi Kinerja Sumber Daya Manusia. Bandung: PT.Refika Aditama.

Notoatmodjo S. 2000. Konsep Perilaku Kesehatan, Teori dan Aplikasi. Jakarta: Fakultas Kesehatan Masyarakat UI;

Pengurus Pusat Ikatan Bidan Indonesia. 2006. Standar Profesi Bidan Indonesia. Jakarta: PP IBI.

Rachmawati IK. 2008. Manajemen Sumber Daya Manusia. Yogyakarta: ANDI.

Robbins SP. 2003. Perilaku Organisasi. Edisi Lengkap. Alih Bahasa Benyamin Molan. Jakarta: PT Indeks Kelompok Gramedia.

Sedarmayanti. 2008. Manajemen Sumber Daya Manusia. Jakarta: Refika Aditama.

Surani. 2007. Anal isis Karakteristik Individu dan Faktor Intrinsik yang Berhubungan dengan Kinerja Bidan Pelaksana Polikinik Kesehatan Desa dalam Pelayanan Kesehatan di Kabupaten Kendal Tahun 2007 [diunduh tanggal 13 April 2011]. Tersedia dari: http:// eprints.undip.ac.id/17401/1/Endang_Surani.pdf

Winardi J. 2008. Motivasi dan Pemotivasian dalam Manajemen Jakarta: Raja Grafindo Persada. 